Article

\title{
Research on the Temperature Field of High-Voltage High Power Line Start Permanent Magnet Synchronous Machines with Different Rotor Cage Structure
}

\author{
Zhaobin Cao ${ }^{1}{ }^{(1)}$, Weili $\mathrm{Li}^{1}$, Jinyang $\mathrm{Li}^{2}$, Xiaochen Zhang ${ }^{1, *}$, Dong $\mathrm{Li}^{1}$ and Meiwei Zhang ${ }^{1}$ \\ 1 School of Electrical Engineering, Beijing Jiaotong University, Beijing 100044, China; \\ 13117369@bjtu.edu.cn (Z.C.); wlli@bjtu.edu.cn (W.L.); lidong223@bjtu.edu.cn (D.L.); \\ 17117395@bjtu.edu.cn (M.Z.) \\ 2 School of Electrical Engineering \& Automation, Harbin Institute of Technology, Harbin 150001, China; \\ Jinyang_yx@163.com \\ * Correspondence: 18201600180@126.com; Tel.: +86-010-5168-5723
}

Received: 13 October 2017; Accepted: 8 November 2017; Published: 10 November 2017

\begin{abstract}
For line start permanent magnet synchronous machines (LSPMSMs), the eddy current loss in the rotor, which has of significant effects on rotor working temperature, may cause thermal demagnetization to permanent magnet. Therefore, this paper addresses an investigation on the temperature distribution in LSPMSM based on a $6 \mathrm{kV}, 315 \mathrm{~kW}$ prototype with solid starting cage bar. Firstly, the loss distributions, obtained from a 2-D transient electromagnetic field calculation, are determined as the distributed heat source in thermal analyses. Then, the fluid-thermal coupled analyses are performed, by which the temperature distributions in the machine are determined. Meanwhile, the calculated motor performance is verified via comparison with the measured results. The calculation results show that the temperatures in the rotor core and permanent magnets are relatively high. To find the solution for reducing the rotor working temperature, a rotor air slot structure was proposed in this analysis. The theoretical calculation indicates that the rotor working temperature reduction is obvious with the rotor air slot in the machine. Therefore, the operating situation of solid rotor LSPMSM could be improved effectively with the proposed rotor thermal solution, which also benefits the machine reliability and safety.
\end{abstract}

Keywords: solid rotor; high voltage permanent magnet motor; transient electromagnetic field; temperature field

\section{Introduction}

High voltage high power line start permanent magnet synchronous machines (LSPMSMs) have been used in various applications such as pumps, fans, and compressors [1]. LSPMSMs have become a research hotspot due to their advantages as line-starting, simple structure, high efficiency, energy density, dynamic capability, and so on [2-10]. The pole-changing starting-method was used in line-start permanent magnet motors to eliminate poor starting torque, vibration at start-up and synchronization problems [11]. An optimization study on interior permanent magnet (IPM) shape and the curvature angle has been done to improve the solid rotor IPM machine structural performance [12]. The slotless double-sided structure is used in line-start solid-rotor axial-flux permanent-magnet (AFPM) motor for high torque density and stable operation. The design allows the motor to operate at both starting and synchronous speeds [13].

Recently, a number of works have been published about permanent magnet synchronous machines (PMSMs) [14-23]. However, most of these studies are focused on the electromagnetic 
design and performance analyses, but ignoring the thermal investigation. To find a successful motor design scheme and ensure a long operating lifetime for LSPMSMs, it is necessary to investigate the thermal issue of the motor and obtain an accurate prediction about the temperature distribution in the motor.

In this paper, thermal investigations are performed on the LSPMSMs. To find the solution to solve the problem of the high working temperature in the rotor, a novel heat transfer structure of rotor air slot is proposed; taking a $6 \mathrm{kV}, 315 \mathrm{~kW}$ LSPMSM with solid rotor for the case study. The two dimensional (2-D) transient electromagnetic field calculation models of the LSPMSMs with solid starting cage bar and rotor air slot are established, respectively, and the transient electromagnetic fields are calculated via the time-stepping finite element analyzing. The loss distributions obtained are taken as the heat source in thermal analyses. Then, the temperature fields of LSPMSMs with different rotor structures are analyzed comparatively. From the results obtained, the working improvement of magnets and solid rotor could be confirmed. The conclusions obtained could provide theoretical basis for the design and optimization of LSPMSM, and also benefit thermal studies on permanent magnet motors.

\section{Electromagnetic Field Calculation}

For the LSPMSM studied in this paper, its stator core geometry is similar to that of normal high voltage induction motor with axial-radial ventilation system. Whereas the rotor, as illustrated in Figure 1 , has an interior permanent magnet structure. Both the rotor wedges and starting cage bars are made of brass, which can benefit motor starting performance. The basic parameters of the $315 \mathrm{~kW}$, $6 \mathrm{kV}$ LSPMSM prototype are listed in Table 1.

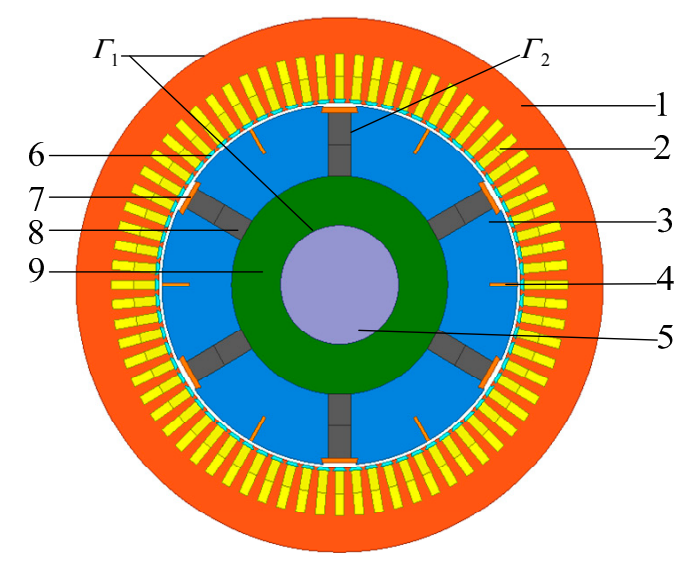

Figure 1. Two dimensional electromagnetic model of the machine: 1 -Stator core; 2 -Stator windings; 3-Solid rotor; 4-Solid starting cage bar; 5-Shaft; 6-Stator slot wedge; 7-Rotor slot wedge; 8-Permanent magnet; 9-Magnetism isolating sleeve.

Table 1. The main parameters of line start permanent magnet synchronous machines (LSPMSMs).

\begin{tabular}{ccc}
\hline Symbol & Quantity & Values and Unit \\
\hline$P_{N}$ & Rated Power & $315 \mathrm{~kW}$ \\
$U_{N}$ & Rated Voltage & $6000 \mathrm{~V}$ \\
$D_{1}$ & Outside diameter of stator & $670 \mathrm{~mm}$ \\
$D_{i 1}$ & Inner diameter of stator & $460 \mathrm{~mm}$ \\
$P$ & Poles & 6 \\
$f$ & Frequency & $50 \mathrm{~Hz}$ \\
$\delta$ & Air gap & $4.2 \mathrm{~mm}$ \\
$L$ & Core length & $550 \mathrm{~mm}$ \\
$n_{k}$ & Number of stator radial ventilation ducts & 6 \\
$b_{k}$ & Stator radial ventilation duct width & $10 \mathrm{~mm}$ \\
\hline
\end{tabular}


For the convenience of finite element analysis (FEA), and considering the actual situation of the motor, the following assumptions are proposed [14]:

(1) The influence of the displacement current and the skin effect in the stator windings are ignored.

(2) Materials are isotropic.

(3) The effects of temperature on the conductivity and permeability of the material are ignored, and the properties of materials are considered those at the assumed working temperature.

Considering the saturation of the magnetic flux, the transient 2-D electromagnetic field calculation equation in complex form would be:

$$
\left\{\begin{array}{c}
\Omega: \frac{\partial}{\partial x}\left(\frac{1}{\mu} \frac{\partial A_{z}}{\partial x}\right)+\frac{\partial}{\partial y}\left(\frac{1}{\mu} \frac{\partial A_{z}}{\partial y}\right)=-\left(J_{z}-\sigma \frac{d A_{z}}{d t}\right) \\
\Gamma_{1}: A_{z}=0 \\
\Gamma_{2}: \frac{1}{\mu_{1}} \frac{\partial A_{z}}{\partial n}-\frac{1}{\mu_{2}} \frac{\partial A_{z}}{\partial n}=J_{s}
\end{array},\right.
$$

where, $\Omega$ is the solving region, $A_{z}$ and $J_{z}$ are magnetic vector potential and the source current density in the z-axial component. $\mu$ is permeability, $\sigma$ is the conductivity, $\Gamma_{1}$ is the boundary of stator outer circle and rotor inner circle, $\Gamma_{2}$ is the boundary of permanent magnet, $J_{s}$ is equivalent current density of the permanent magnet, $\mu_{1}$ and $\mu_{2}$ are relative permeability.

Since both the performance and temperature accuracy predictions depend on the accuracy of the determined loss, the 2-D electromagnetic FEA is employed in this investigation. The core loss of each element can be calculated by the Steinmetz equation [15], as shown in (2), and stator core loss could be the sum of all element losses within stator core region:

$$
P_{\text {core }}=k_{h} f B_{m}^{n}+k_{e} f^{2} B_{m}^{2}+k_{a} f^{1.5} B_{m}^{1.5}
$$

where, $P_{\text {core }}$ is the stator core loss, $B_{m}$ is the flux density magnitude, $k_{h}, k_{e}$ and $k_{a}$ are hysteresis coefficient, eddy current coefficient and the excess loss coefficient. $n$ is the Steinmetz constant.

According to [16], the joule losses in the stator windings can be calculated by:

$$
P_{\text {joule }}=3 \times R_{T} \times I_{R M S}^{2},
$$

where, $P_{\text {joule }}$ are the stator joule losses, and $I_{R M S}$ is the root mean square (RMS) value of the phase current. $R_{T}$ is the value of the stator coil resistance at temperature $T$.

During the calculation, the eddy current losses in solid rotor core, wedges, cage bars and permanent magnet caused by the harmonics in the air-gap field can be calculated by (4) in a cycle [17]:

$$
P_{e}=\frac{1}{T_{e}} \int_{T_{e}} \sum_{i=1}^{k} J_{e}^{2} \Delta_{e} \sigma_{r}^{-1} l_{t} d t
$$

where, $P_{e}$ is the rotor eddy current losses (in W), $J_{e}$ is the current density in each element (in $\mathrm{A} / \mathrm{m}^{2}$ ), $\Delta_{e}$ is the element area (in $\left.\mathrm{m}^{2}\right), l_{t}$ is the rotor axial length (in meters), $\sigma_{r}$ is the conductivity of the eddy current zone (in $\mathrm{S} / \mathrm{m}$ ), and $T_{e}$ is the cycle of time.

According to [16], friction and windage losses, that is, $\mathrm{Pw}$, mainly depend on the size of the fan and the mechanical speed of the machine. Besides, with the electromagnetic losses (the stator core loss, the stator copper loss and the rotor loss) obtained from the above analyses, the loss distribution in LSPMSM under rated operating is determined, as shown in Table 2, which are taken as the distributed heat generation sources in the fluid-thermal coupling analysis. 
Table 2. Losses in LSPMSM while in operation with rated load (W).

\begin{tabular}{ccccccc}
\hline \multirow{2}{*}{$\begin{array}{c}\text { Copper } \\
\text { Loss }\end{array}$} & Iron & Friction & \multicolumn{4}{c}{ Eddy Current Loss } \\
\cline { 4 - 6 } & Loss & Loss & $\begin{array}{c}\text { Solid } \\
\text { Rotor }\end{array}$ & $\begin{array}{c}\text { Rotor Slot } \\
\text { Wedge }\end{array}$ & $\begin{array}{c}\text { Solid Starting } \\
\text { Cage Bar }\end{array}$ & $\begin{array}{c}\text { Permanent } \\
\text { Magnet }\end{array}$ \\
\hline 4389 & 5412 & 6866 & 2724 & 454 & 83 & 45 \\
\hline
\end{tabular}

\section{Fluid-Thermal Analysis}

Because of the complicated structure and the rotation of the rotor, the movement of air in the LSPMSM is extremely complicated. Therefore, in this investigation the accurate fluid-thermal coupling calculations are performed.

The machine adopts an air-cooled hybrid ventilation system, including the inner loop and the outer loop, as shown in Figure 2.

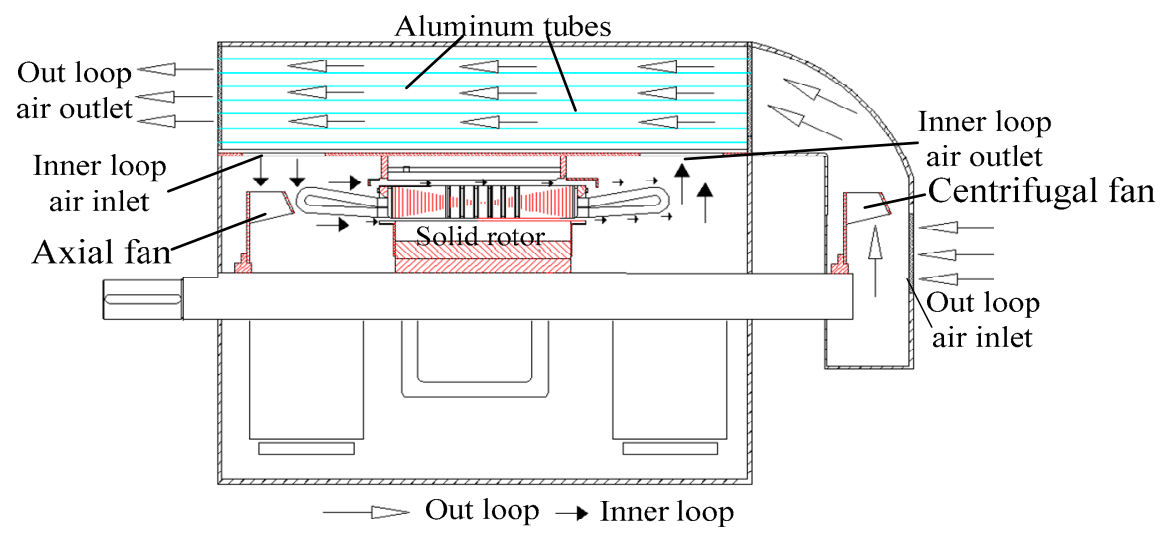

Figure 2. Cooling system structure in LSPMSM.

In the out loop of the cooling system, the cooling air, driven by the centrifugal fan, goes into the aluminum air-cooled tubes, by which the heat of inner loop hot air is exchanged. And finally, the out loop-cooling air flows into the atmosphere from the other end of the aluminum tubes.

For the inner loop, the cooling air flows into the machine from the air inlet forced by the axial fan, and passes the air-gap and stator axial ventilation ducts. The hot air flows into the cooler through the air outlet, and then back into the air inlet after the heat exchange, by which the cooling system cycle is completed.

\subsection{Assumed Conditions}

The following assumptions are proposed based on practical engineering:

(1) The effects of the cooling medium buoyancy and gravity on the fluid flow are ignored.

(2) The flow rate of the medium in the cooling system is much less than that of the sound velocity, so the fluid is treated as an incompressible fluid.

(3) The steady equilibrium state of the fluid and heat transfer in the cooling system is studied, the mathematical model is aimed at the steady flow of the fluid, and the quantity of the equation does not change with time.

According to the characteristics of the machine structure, fluid flow and heat transfer in cooling system, the boundary conditions are given as follows:

(4) The given fluid mass flow rated is chosen as let boundary.

(5) The given fluid pressure is selected as the outlet boundary conditions. 


\subsection{Modeling of Flued Thermal Coupling Analyses}

During the calculation, the laws of the conservation of mass, the conservation of momentum, and the conservation of energy should be satisfied. The calculation control equations for fluid-thermal coupling analysis are shown as [18]:

$$
\left\{\begin{array}{l}
\frac{\partial \rho}{\partial t}+\operatorname{div}(\rho \boldsymbol{u})=0 \\
\frac{\partial(\rho u)}{\partial t}+\operatorname{div}(\rho u \boldsymbol{u})=\operatorname{div}(\phi g r a d u)-\frac{\partial P}{\partial x}+S_{u} \\
\frac{\partial(\rho v)}{\partial t}+\operatorname{div}(\rho \boldsymbol{u} v)=\operatorname{div}(\phi g r a d v)-\frac{\partial P}{\partial y}+S_{v} \\
\frac{\partial(\rho w)}{\partial t}+\operatorname{div}(\rho \boldsymbol{u} w)=\operatorname{div}(\phi g r a d w)-\frac{\partial P}{\partial z}+S_{w} \\
\frac{\partial(\rho T)}{\partial t}+\operatorname{div}(\rho \boldsymbol{u} T)=\operatorname{div}\left(\frac{\lambda}{c} \operatorname{grad} T\right)+S_{T}
\end{array},\right.
$$

where, $\rho$ is the fluid density $\left(\mathrm{kg} / \mathrm{m}^{3}\right)$; $u$ is the velocity vector, $u, v, w$ are the velocity vector $u$ in the $\mathrm{x}$, $\mathrm{y}, \mathrm{z}$, direction of the component (m/s), $P$ is the fluid pressure $(\mathrm{Pa}), S_{u}, S_{v}, S_{w}$ are the conservation of momentum of the generalized source term in all directions, $S_{T}$ is the heat source for energy equation, $\phi$ is the dynamic viscosity coefficient $[\mathrm{kg} /(\mathrm{m} \cdot \mathrm{s})], \lambda$ is the thermal conductivity $[\mathrm{W} /(\mathrm{m} \cdot \mathrm{K})], c$ is the specific heat $\left[\mathrm{J} /\left(\mathrm{kg} \cdot{ }^{\circ} \mathrm{C}\right)\right], \mathrm{T}$ is the temperature $\left({ }^{\circ} \mathrm{C}\right)$.

To solve the regional air flow in the turbulent state, turbulence is simulated with the standard $k-\varepsilon$ model [19]:

$$
\left\{\begin{array}{c}
\frac{\partial}{\partial t}(\rho k)+\operatorname{div}(\rho k u)=\operatorname{div}\left[\left(\mu+\frac{\mu_{t}}{\sigma_{k}}\right) g r a d k\right]+G_{k}-\rho \varepsilon \\
\frac{\partial}{\partial t}(\rho \varepsilon)+\operatorname{div}(\rho u \varepsilon)=\operatorname{div}\left[\left(\mu+\frac{\mu_{t}}{\sigma_{\varepsilon}}\right)\right]+G_{1 \varepsilon} \frac{\varepsilon}{k} G_{k}-G_{2 \varepsilon} \rho \frac{\varepsilon^{2}}{k}
\end{array},\right.
$$

where, $k$ is the turbulent kinetic energy, $\varepsilon$ is the diffusion factor, $G_{k}$ is the turbulence dissipation rate, $G_{1 \varepsilon}, G_{2 \varepsilon}$ are constants, $\sigma_{k}$ and $\sigma_{\varepsilon}$ are the Planck constants.

Due to the complex ventilation system, in the modeling for fluid-thermal coupled investigation, the motor and the cooler are divided into two parts, as shown in Figure 3.

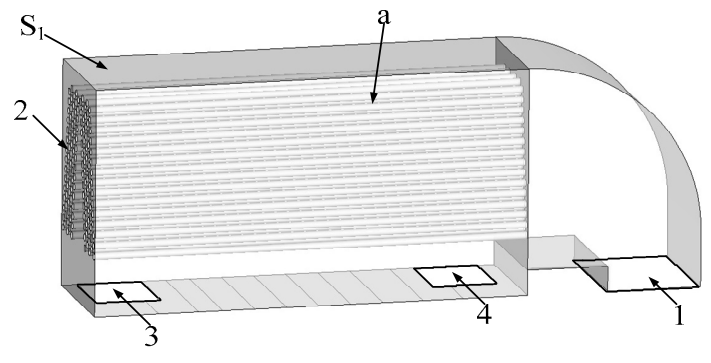

(a)

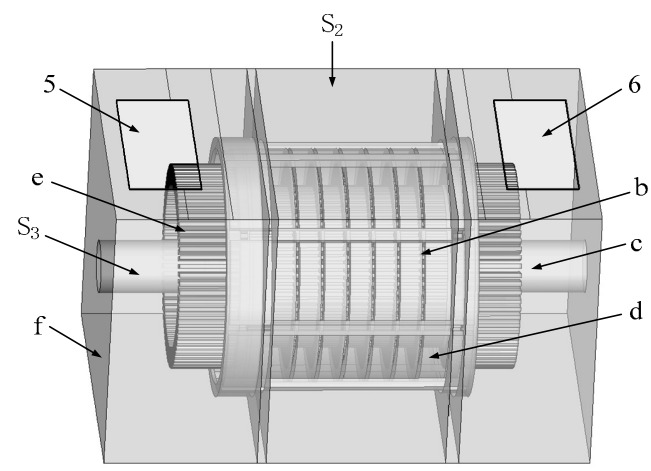

(b)

Figure 3. Three dimensional fluid solid coupling heat transfer calculation model for LSPMSM: (a) Computational model of coupled heat transfer between fluid and solid in cooler; (b) Computational model of coupling heat transfer between fluid and solid. 1-Out loop air inlet, 2-Out loop air outlet, 3-Inner loop air inlet of cooler, 4-Inner loop air outlet of cooler, 5-Inner loop air outlet of motor, 6-Inner loop air inlet of motor, a-Aluminum tubes, b-Stator radial duct, c-Shaft, $\mathrm{d}$-Stator core, e-Stator winding, $\mathrm{f}$-Shell.

The boundary conditions at the fluid entrance and exit of the cooler in the two models are the same. These are: the inner loop air inlet surface in the motor part model (No. 5 face) and the inner loop air outlet surface in the cooler part model (No. 3 face) are with the same boundary IV, and the inner loop air outlet surface in the motor part model (No. 6 face) and the inner loop air inlet surface in the cooler part model (No. 4 face) are with the same boundary V. 


\subsection{Temperature in LSPMSM with Solid Starting Cage Bar}

From the fluid-thermal coupling analysis by using the Finite Volume Method, the fluid flowing and the whole region 3-D temperature distribution in the LSPMSM under rated operating are obtained, when with an ambient temperature of $28^{\circ} \mathrm{C}$.

The radial velocities of fluid in the stator radial ventilation duct, from stator core inner surface to back yoke outer surface, are shown in Figure 4. From the fan end $(0 \mathrm{~mm})$ to the non-fan end $(550 \mathrm{~mm})$, the stator radial ventilation ducts are numbered No. 1 to No. 6. For the convenience of research, assume that the stator radial ducts in which the air flowing from stator teeth to stator yoke are defined as the out-wind zone, whereas for the ducts with fluid flowing from stator yoke to teeth are defined as in-wind zone.

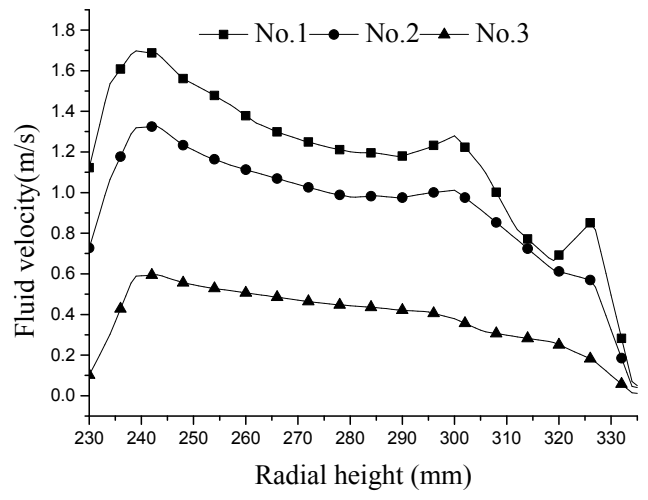

(a)

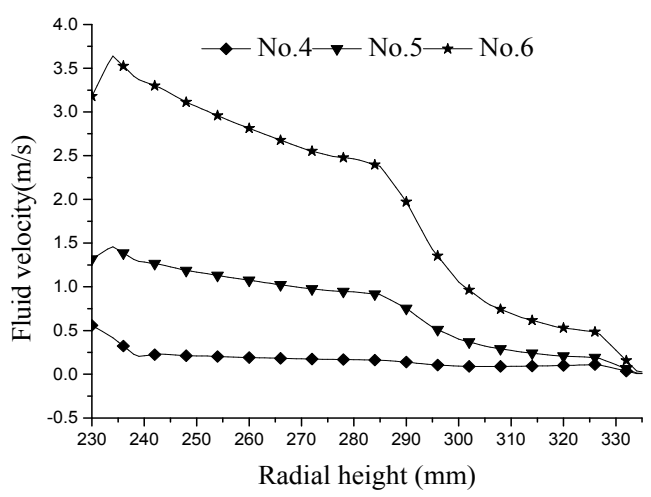

(b)

Figure 4. The profile of the flow velocity along the radial direction of the stator radial ventilation ducts:

(a) fluid velocities in No. 1, No. 2, No. 3 ducts; (b) fluid velocities in No. 4, No. 5, No. 6 ducts.

In No. 6 radial duct, the fluid has the largest velocity of around $3.7 \mathrm{~m} / \mathrm{s}$, and the cooling effect of this duct should be better. However, the lowest temperature of the stator core does not appear within this region, because this duct is so close to the non-fan end that the inside flowed cooling air temperature has risen a lot through the previous ventilation ducts. The flow velocity in the No. 1 duct which is close to the fan end is lower just than that in No. 6 duct, but the lowest temperature is located in this region. For the lowest fluid flowing velocity, it appears in the No. 4 stator radial duct, which may result the highest temperature of motor appears near the No. 4 stator radial duct.

The axial distributions of fluid velocity and temperature in both the stator yoke back ventilation duct and air-gap are shown in Figure 5a,b, respectively.

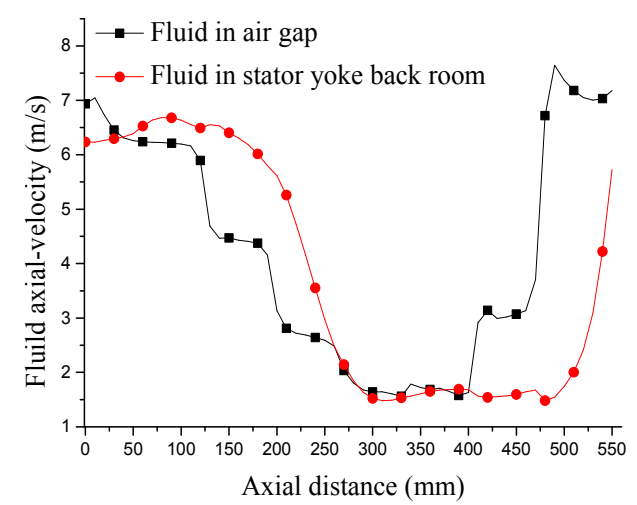

(a)

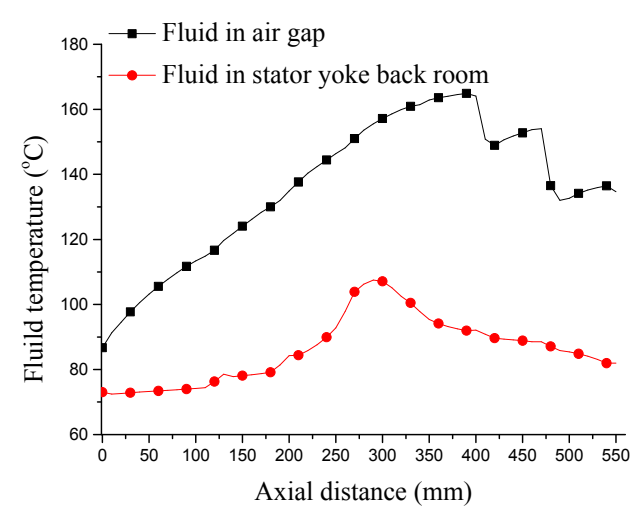

(b)

Figure 5. (a) Axial velocity of fluid in LSPMSM under rated operating; (b) Axial temperature distribution of fluid in LSPMSM under rated operating. 
In the stator core length region $(0-550 \mathrm{~mm})$, the axial velocity of fluid in the air-gap is decreasing first and then rising. This is due to the parts of fluid in the air-gap flowing to the stator yoke back through the No. 1, No. 2 and No. 3 radial ducts, which reduces the cooling air in the air-gap, and then some of fluid in stator yoke flows back to air-gap through the No. 4, No. 5 and No. 6 radial ducts to the air-gap which increases the cooling medium in the air-gap. Therefore, No. 1, No. 2 and No. 3 stator radial ducts belong to the out-wind zone, and No. 4, No. 5 and No. 6 stator radial duct belong to in-wind zone.

Affected by the heat generated in the solid rotor, the temperature of fluid in the air-gap is much higher than that of fluid in stator yoke back.

The fluid movements within the air-gap and stator radial ventilation ducts have great impacts on the heat transmissions in stator teeth, stator winding and solid rotor.

Figure 6 shows the circumferential average temperature distributions in stator windings along the axial direction. The temperatures of both the stator upper windings and the stator lower windings are relatively high. The highest temperature of the upper windings is $150.9^{\circ} \mathrm{C}$, while the highest temperature of the lower windings is $149.5^{\circ} \mathrm{C}$. The reason for this is that the flow velocity in the No. 4 stator radial duct is the lowest, which results in a relatively poorer heat dissipation in this area (270-400 mm).

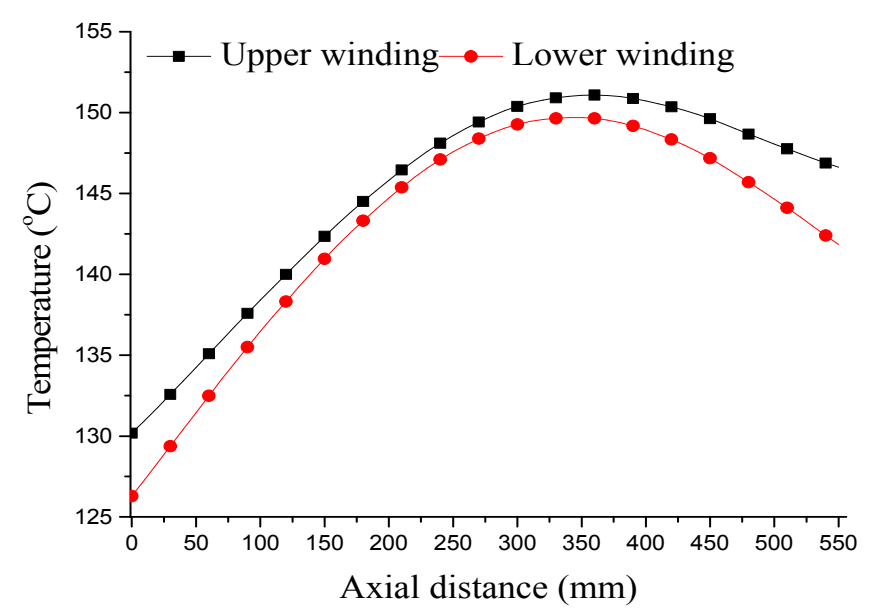

Figure 6. Axial temperature distribution of Stator windings in LSPMSM.

The temperature distributions of the stator and rotor are shown in Figure 7. Due to the poor heat transfer capacity of the air in the air-gap, the stator cooling system has little influence on the rotor, thus the highest temperature inside this domain appears in the rotor, which is about $178.9^{\circ} \mathrm{C}$. Affected by the stator radial ventilation ducts and stator yoke back ventilation ducts directly, the stator region temperature varies between $110{ }^{\circ} \mathrm{C}$ and $152^{\circ} \mathrm{C}$.

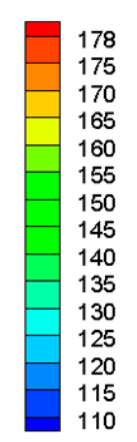

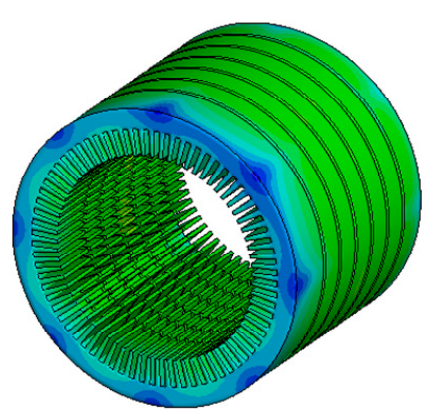

(a)

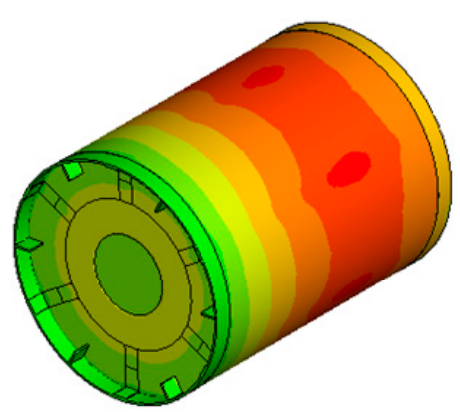

(b)

Figure 7. 3-D temperature distribution in solid region of analysis model: (a) Stator; (b) Rotor. 
Figure 8 shows the temperature variations along the radial direction from the rotor core inner circle to the stator yoke outer surface at axial positions of $\mathrm{L}=0 \mathrm{~mm}, \mathrm{~L}=250 \mathrm{~mm}, \mathrm{~L}=550 \mathrm{~mm}$. In rotor core (ac section in the curves), the temperature is rising gradually along the radial direction $(\mathrm{L}=250 \mathrm{~mm})$, and the temperature reaches its highest at rotor core surface (c point in the curve) and the highest temperatures at different axial positions are $156{ }^{\circ} \mathrm{C}(\mathrm{L}=0 \mathrm{~mm}), 176.8^{\circ} \mathrm{C}(\mathrm{L}=250 \mathrm{~mm})$ and $170.4{ }^{\circ} \mathrm{C}$ $(\mathrm{L}=550 \mathrm{~mm})$, respectively.
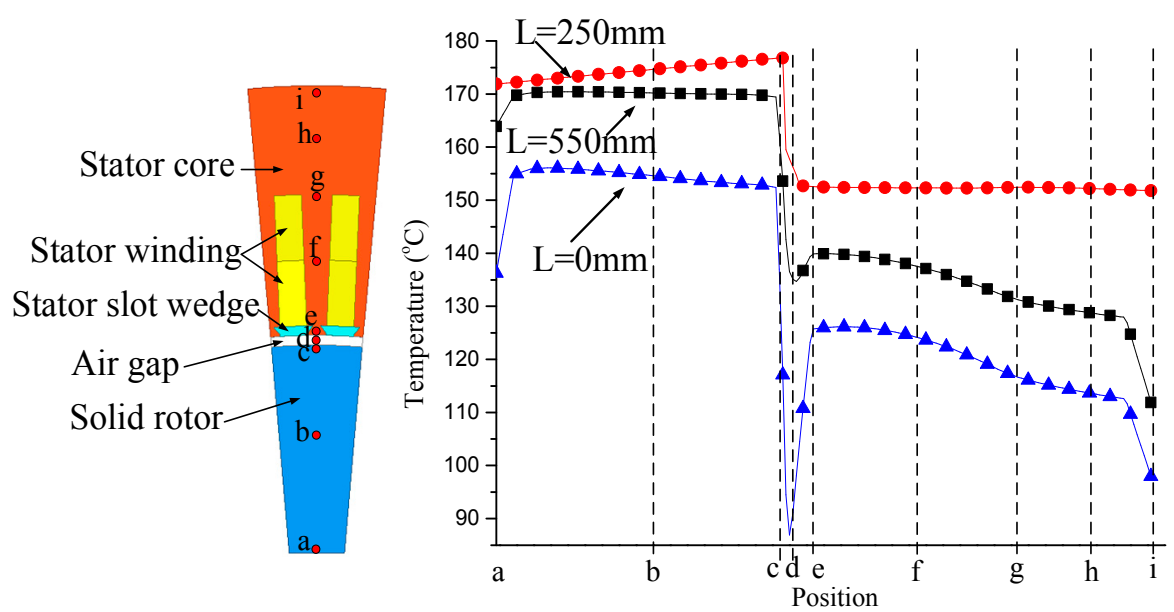

Figure 8. Temperature distribution along the radial direction.

Though the effects of rotor rotation are considered in this investigation, the temperature of the fluid in the air-gap changes violently, and the temperature gradient decreases significantly in the cd section, and the temperature increases gradually in the de section (stator tooth top). The temperatures decrease to $87^{\circ} \mathrm{C}(\mathrm{L}=0 \mathrm{~mm}), 151.8^{\circ} \mathrm{C}(\mathrm{L}=250 \mathrm{~mm})$ and $111.8^{\circ} \mathrm{C}(\mathrm{L}=550 \mathrm{~mm})$ in the cd section at different axial positions.

Whereas in the stator core region the temperature drops gradually, and temperature differences in tooth eg section and yoke gi section are $28.1{ }^{\circ} \mathrm{C}(\mathrm{L}=0 \mathrm{~mm}), 0.7{ }^{\circ} \mathrm{C}(\mathrm{L}=250 \mathrm{~mm}), 28.2{ }^{\circ} \mathrm{C}$ $(\mathrm{L}=550 \mathrm{~mm})$, respectively.

In order to verify the calculated results, six negative temperature coefficient (NTC) thermistors were embedded in the permanent magnet of LSPMSM prototype, the practical test rig and facilities are shown in Figure 9.

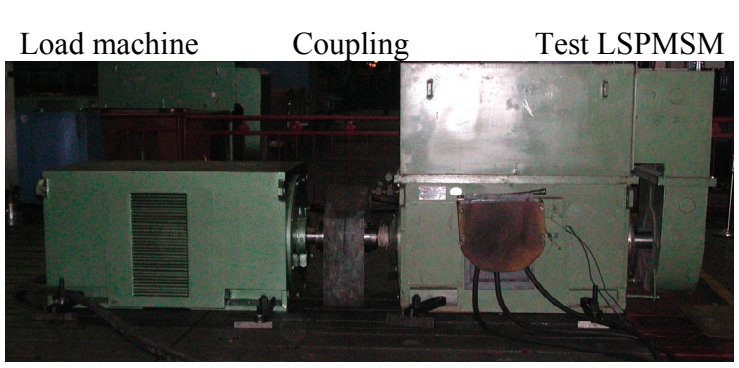

(a)

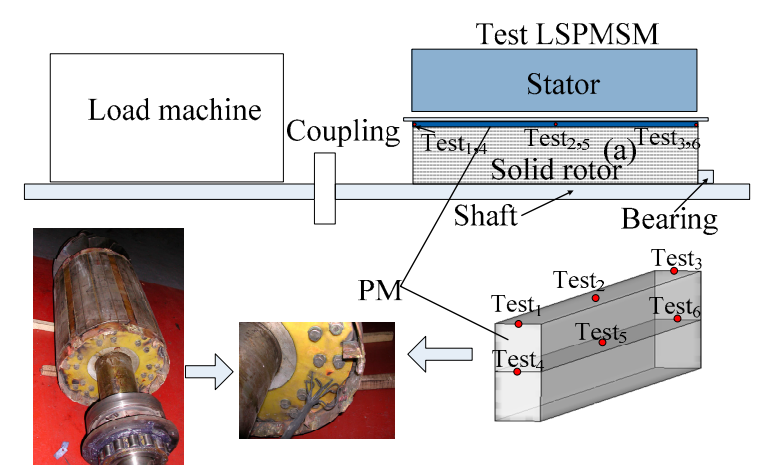

(b)

Figure 9. (a) Experimental test bench (LSPMSM); (b) Thermocouples location. 
The Test 1 and Test 4 thermistors are located at the permanent magnets near the fan end. The Test2 and Test 5 thermistors are located at the axial center position of the permanent magnets. The Test 3 and Test 6 thermistors are located at the permanent magnet near the axle stretch end. When the components in the motor reach thermal stability, then the motor stops and measures the temperature at different heat locations immediately through the embedded thermocouples. At the temperature measurement locations, the measured temperature value and the calculated results are compared, as shown in Table 3.

Table 3. Comparison between the measured values and the calculated results of permanent magnet temperature measuring points $\left({ }^{\circ} \mathrm{C}\right)$.

\begin{tabular}{ccc}
\hline Measuring Point & Measured Value & Calculated Value \\
\hline Test1 & 144.7 & 150 \\
Test2 & 181.4 & 176 \\
Test3 & 176.7 & 171 \\
Test4 & 142.7 & 154 \\
Test5 & 168.7 & 169 \\
Test6 & 169.5 & 170 \\
\hline
\end{tabular}

It can be seen that the calculated results are close to the test data, which meets the actual accuracy requirement of industrial applications, and indicates that the boundary conditions, loss results and the method are correct and reliable.

The reasons for errors mainly are installation error and the unsmooth processing of the permanent magnets. In addition, end structure deformation can also cause uneven electro- magnetic loss distribution to an actual operation. These may lead to the temperature distribution asymmetry at the test point, as well as the difference from the calculated results.

\subsection{Temperature in LSPMSM with Rotor Air Slot}

From the above analyses, the temperature of solid rotor and permanent magnet of LSPMSM with solid starting cage bar is relatively high. The permanent magnet may be demagnetized due to the long time operation at high temperature. Then, the reliability of LSPMSM will be affected.

Based on the original design, the rotor air slot structure for rotor heat transmission is proposed and investigated. The two dimensional transient electromagnetic field of high-voltage high power LSPMSM with rotor air slot is calculated via the time-stepping finite element analyzing. Electromagnetic analyses results show that the machine can still pull in sync, and such rotor air slot structure has little influence on the machine electromagnetic loss and performance of the machine, so in the calculation of fluid-thermal numerical analysis, the distributed heat generation sources still use the data in Table 2 .

By using the same method, the fluent-thermal coupled analyses on the new structure machine are performed, and the velocity and temperature distributions of the cooling medium within the fluid region are obtained. Figure 10 shows the velocity distribution in the rotor air slot along the axial direction. 


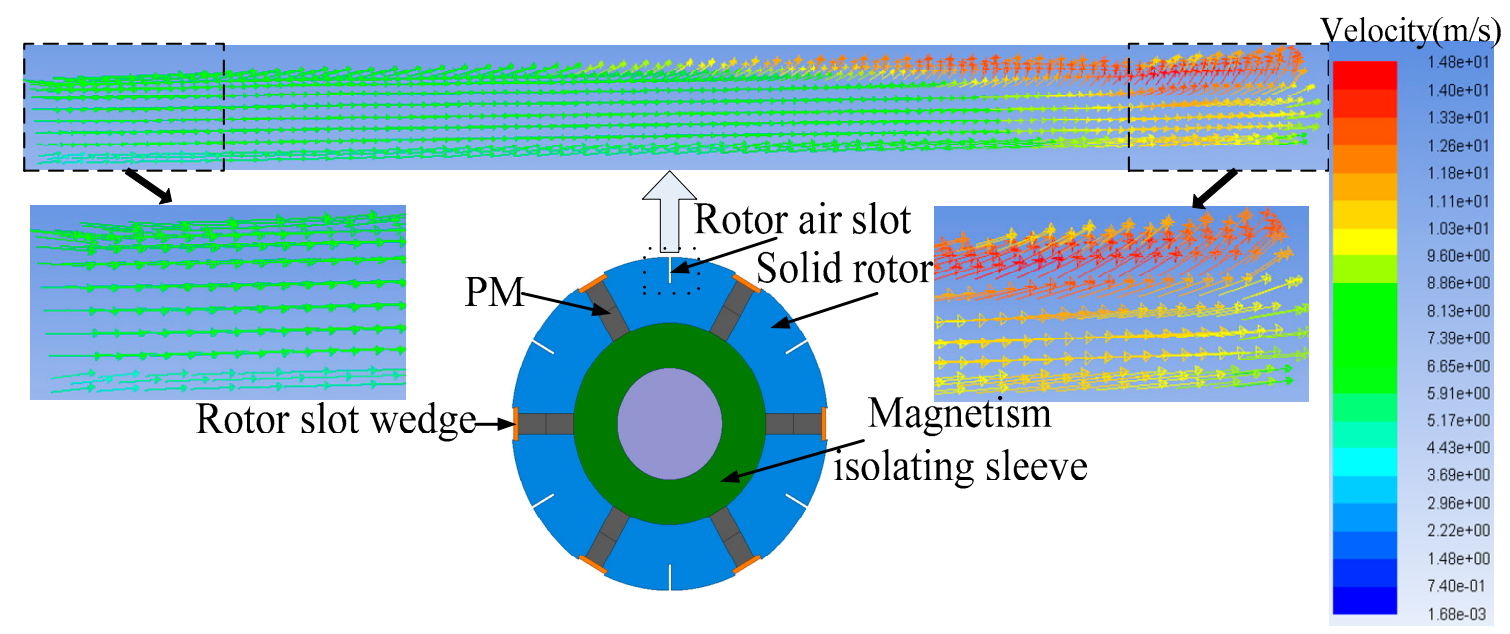

Figure 10. The velocity distribution in the rotor air slot along the axial direction.

In Figure 10, at the fan end of the machine, the axial velocity at the entrance of the rotor air slot is large, which means the fluid in rotor air slots flows mainly along the axial direction. Whereas for the fluid at the non-fan end, the axis velocity in the rotor air slot is smaller. Meanwhile, affected by the centrifugal force from rotor rotating, the fluid in the rotor air slot would be thrown into the air-gap, by which the heat in the rotor would be transferred via the flowing cooling air to the stator. Also, the fluid velocity in the air-gap would be increased, which could benefit the stator heat transmission.

The cooling air from rotor slots will also enter into stator radial ducts through the air-gap, and change the fluid flowing and heat transmission in the stator side. The variation curves of fluid radial velocity in the different stator ducts are shown in Figure 11.

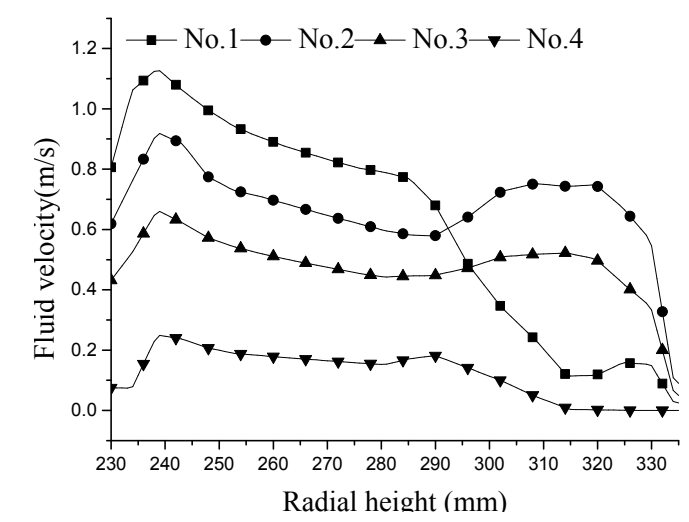

(a)

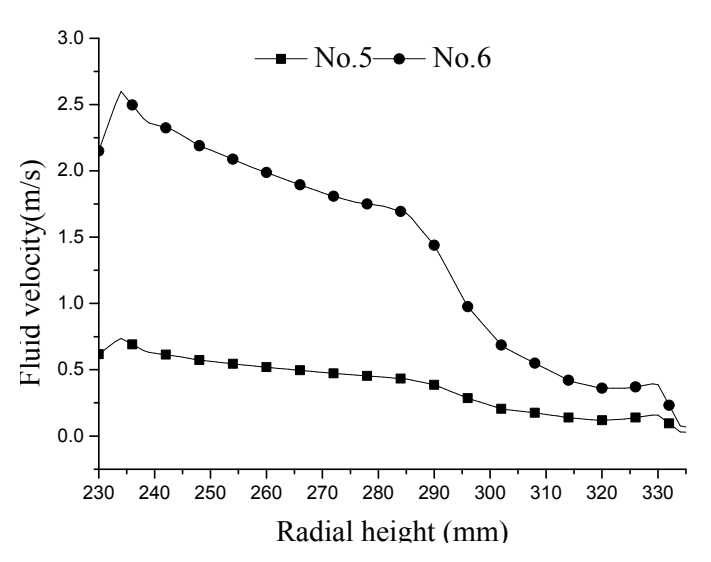

(b)

Figure 11. The profile of the flow velocity along the radial direction of the stator radial ventilation ducts: (a) No. 1, No. 2, No. 3, and No. 4 stator radial ducts; (b) No. 5, No. 6 stator radial ducts.

When the LSPMSM has air slot in the rotor, the fluid in the No. 1, No. 2, No. 3, and No. 4 stator radial ducts are flowing from air-gap side to stator yoke, thus those ducts within the out-wind zone, whereas for No. 5 and No. 6 stator radial ducts, they belong to the in-wind zone. In Figure 11, the radial velocity of fluid in the stator radial ventilation ducts changes significantly along the axial direction, and the largest fluid radial velocity, which is about $2.59 \mathrm{~m} / \mathrm{s}$ located in the No. 6 duct, declined.

The axial distribution curves of fluid velocity and temperature in the stator yoke back ventilation ducts and air-gap are shown in Figure 12a,b, respectively. 


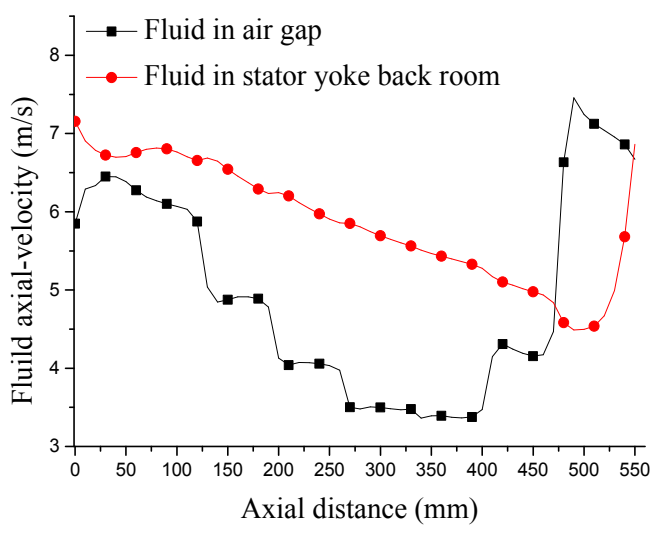

(a)

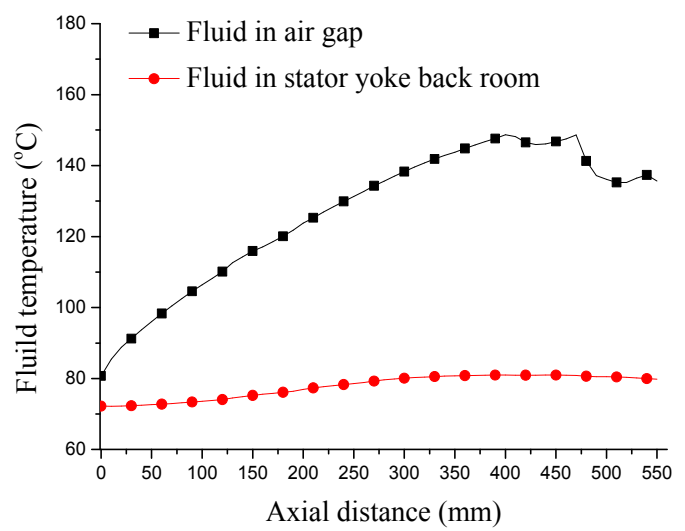

(b)

Figure 12. (a) Axial velocity of cooling medium in LSPMSM with rotor air slot under rated operating description of what is contained in the first panel; (b) Axial temperature distribution of cooling medium in LSPMSM with rotor air slot under rated operating.

From the analyses above, parts of fluid in the air-gap flow to the stator yoke back through No. 1, No. 2, No. 3, No. 4 ducts, thus, in Figure 12, the axial velocity of fluid in the air-gap decrease first, but then they increased because parts of the fluid in the stator yoke flow back to the air-gap through No. 5 and No. 6 ducts.

Besides, the fluid temperature variations in the air-gap and stator yoke back in LSPMSM with rotor air slot are essentially similar to that in LSPMSM with solid starting cage bar shown in Figure 5b.

The temperature distributions in machine windings are shown in Figure 13. The upper windings temperature is higher than that of lower windings, and the trend of the temperature change of the stator windings in Figure 13 is similar to that in Figure 6. Figure 14 shows the temperature distribution in the solid region of LSPMSM with rotor air slot.

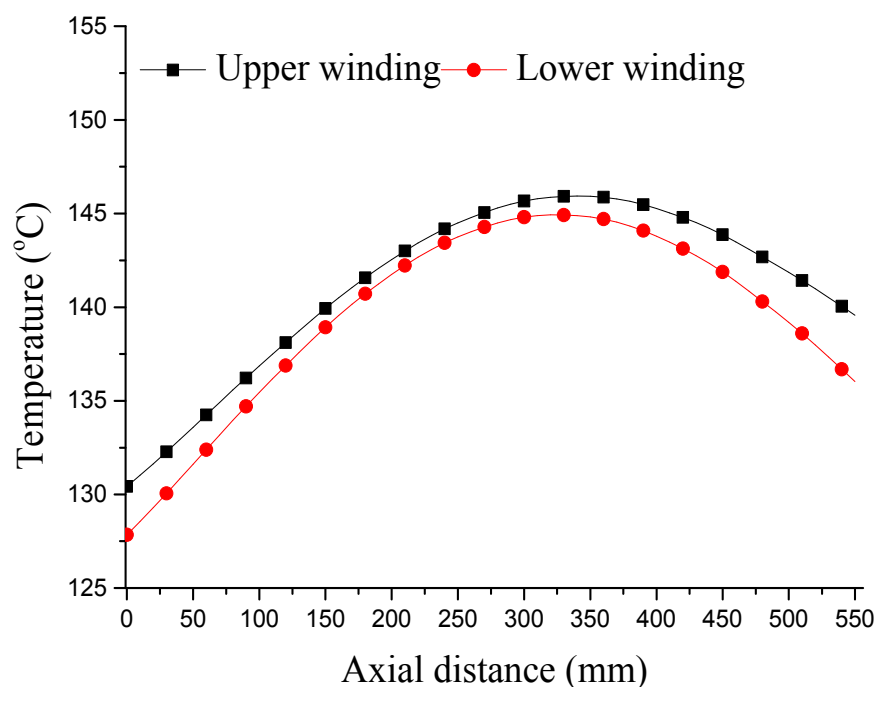

Figure 13. Axial temperature distribution of Stator windings in LSPMSM with rotor air slot. 


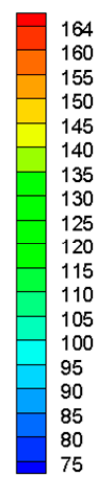

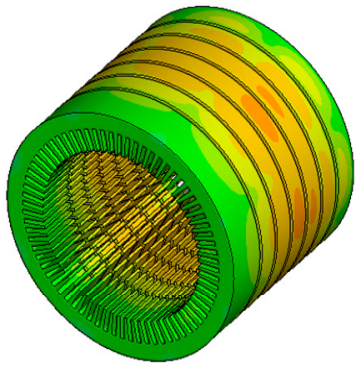

(a)

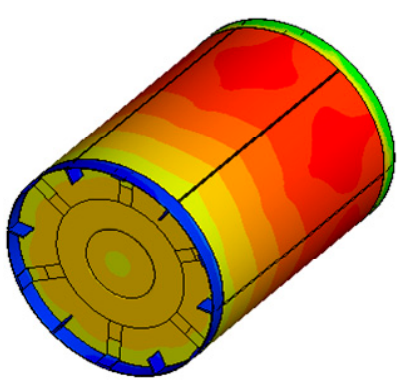

(b)

Figure 14. 3-D temperature distribution in solid region of analysis model: (a) Stator; (b) Rotor.

Compared with the calculated results of the temperature field of the original machine, in the LSPMSM with rotor air slot the temperature of the motor is effectively reduced, especially that in the rotor end ring. Due to the poor heat transfer capacity of the cooling air in the air-gap, the rotor air slot cooling structure has little influence on stator heat transmission, thus the highest temperature inside this domain still appears in the rotor, which is about $164^{\circ} \mathrm{C}$. Affected directly by the cooling system, the rotor region temperature varies between $75{ }^{\circ} \mathrm{C}$ and $164{ }^{\circ} \mathrm{C}$.

In order to more clearly understand the impact of the rotor air slot on the temperature rise of the rotor core and permanent magnets in high-voltage high power LSPMSM, the temperature in machines with two different rotor cage structures are fully compared, as shown in Table 4.

Table 4. Comparison of calculation results of temperature field for two kinds of rotor cage structures.

\begin{tabular}{ccc}
\hline \multirow{2}{*}{ Temperature } & \multicolumn{2}{c}{ Highest Temperature $\left.{ }^{\circ} \mathrm{C}\right)$} \\
\cline { 2 - 3 } Component & Rotor with Solid Rotor Cage Bar & Rotor with Air Slot \\
\hline Stator core & 152 & 152 \\
Stator windings & 150.9 & 150 \\
Rotor core & 178.6 & 164 \\
PM & 178.9 & 164 \\
\hline
\end{tabular}

Table 4 indicates that, compared with LSPMSM with solid starting cage bar, the highest temperature of rotor core and permanent magnet of LSPMSM with rotor air slot dropped $14.6{ }^{\circ} \mathrm{C}$ and $14.9^{\circ} \mathrm{C}$, respectively, which means that the temperature distribution of the rotor is obviously improved by the rotor air slot structure.

\section{Conclusions}

(1) The temperatures in the LSPMSM with solid starting cage bars rise observably along the axial direction. The permanent magnet may be demagnetized due to operating at high temperature for a long time. The axial temperature difference would cause unbalanced thermal stress that cannot be ignored.

(2) The proposed rotor air slot cooling structure could make the cooling medium more effective in heat transmission and promote the highest temperature and the axial temperature difference reduces obvious, thus making the temperature more evenly distributed in the machine.

(3) The highest temperature of the rotor core and permanent magnet dropped $14.6^{\circ} \mathrm{C}$ and $14.9{ }^{\circ} \mathrm{C}$, respectively, and the axial temperature difference gradually decreases in LSPMSM with the proposed rotor air slot structure. This could enhance the temperature distribution in the LSPMSM, and also could provide a reference for cooling system design in electric machines. 
Acknowledgments: This work was supported by the national special project for international scientific and technological cooperation (2015DFR70060) and Natural Science Foundation of Beijing Municipality (3162022).

Author Contributions: Zhaobin Cao implemented simulation; Weili Li supervised all process; Jinyang Li performed the experiments; Xiaochen Zhang and Dong Li analyzed the data; Meiwei Zhang checked paper format.

Conflicts of Interest: The authors declare no conflict of interest.

\section{References}

1. Kurihara, K.; Rahman, M.A. High-efficiency line-start interior permanent-magnet synchronous motors. IEEE Trans. Ind. Appl. 2004, 40, 789-796. [CrossRef]

2. Lee, J.; Lee, H.W. The performance prediction of controlled-PM LSM in various design schemes by FEM. IEEE Trans. Magn. 2000, 36, 1902-1905. [CrossRef]

3. In-Soung, J.; Jin, H.; Dong, S.H. 3-D analysis of permanent magnet linear synchronous motor with magnet arrangement using equivalent magnetic circuit network method. IEEE Trans. Magn. 1999, 35, 3736-3738. [CrossRef]

4. Guo, Y.; Zhu, J.G.; Wu, W. Thermal analysis of SMC motors using a hybrid model with distributed heat sources. IEEE Trans. Magn. 2005, 41, 412124-412128. [CrossRef]

5. Huang, Y.; Zhu, J.G.; Guo, Y. Thermal analysis of high-speed SMC motor based on thermal network and 3-D FEA with rotational core loss included. IEEE Trans. Magn. 2009, 45, 4684-4687. [CrossRef]

6. Marignetti, F. Design of axial flux PM synchronous machines through 3-D coupled electromagnetic thermal and fluid-dynamical finite-element analysis. IEEE Trans. Ind. Electron. 2008, 55, 3591-3601. [CrossRef]

7. Rahman, M.A.; Osheiba, A.M.; Kurihara, K. Advances on single-phase line-start high efficiency interior permanent magnet Motors. IEEE Trans. Ind. Electron. 2012, 59, 1333-1345. [CrossRef]

8. Knight, A.M.; Mcclay, C.I. The design of high-efficiency line-start motors. IEEE Trans. Ind. Appl. 2000, 36, 1555-1562. [CrossRef]

9. Bracikowski, N.; Hecquet, M.; Brochet, P.; Shirinskii, S.V. Multiphysics modeling of a permanent magnet synchronous machine by using lumped models. IEEE Trans. Ind. Electron. 2012, 59, 2426-2437. [CrossRef]

10. Hosoi, T.; Watanabe, H.; Shima, K.; Fukami, T.; Hanaoka, R.; Takata, S. Demagnetization analysis of additional permanent magnets in salient-pole synchronous machines with damper bars under sudden short circuits. IEEE Trans. Ind. Electron. 2012, 59, 2448-2456. [CrossRef]

11. Nima, F.E.; Mojtaba, M.; Aliakbar, D.A. Line-start permanent magnet motors: Proper design for pole-changing starting method. IET Electr. Power Appl. 2013, 7, 470-476. [CrossRef]

12. Arumugam, P.; Xu, Z.; La Rocca, A.; Vakil, G.; Dickinson, M.; Amankwah, E.; Hamiti, T.; Bozhko, S.; Gerada, C.; Pickering, S.J. High-Speed Solid Rotor Permanent Magnet Machines: Concept and Design. IEEE Trans. Electrification 2016, 2, 391-400. [CrossRef]

13. Mahmoudi, A.; Kahourzade, S.; Rahim, N.A.; Hew, W.P.; Uddin, M.N. Design, analysis, and prototyping of a novel-structured solid-rotor-ringed line-start axial-flux permanent-magnet motor. IEEE Trans. Ind. Electron. 2014, 61, 1722-1734. [CrossRef]

14. Li, W.; Zhang, X.; Cheng, S. Study of solid rotor line-start PMSM operating. In Proceedings of the International Conference on Electrical Machines, Wuhan, China, 17-20 October 2008; pp. 1803-1809.

15. Akiror, J.C.; Rahman, T.; Pillay, P. Progress on formulas for core loss calculations. In Proceedings of the 20th International Conference on Electrical Machines, Marseille, France, 2-5 September 2012; pp. 1803-1809.

16. Debruyne, C.; Polikarpova, M. Evaluation of the efficiency of line-start permanent-magnet machines as a function of the operating temperature. IEEE Trans. Ind. Electron. 2014, 61, 4443-4454. [CrossRef]

17. Weili, L.; Hongbo, Q. Influence of copper plating on electromagnetic and temperature fields in a high-speed permanent-magnet generator. IEEE Trans. Magn. 2012, 48, 2247-2253. [CrossRef]

18. Weili, L.; Xiaochen, Z.; Shukang, C.; Junci, C. Thermal optimization for a HSPMG used for distributed generation systems. IEEE Trans. Ind. Electron. 2013, 60, 474-483. [CrossRef]

19. De Donato, G.; Capponi, F.G.; Caricchi, F. No-load performance of axial flux permanent magnet machines mounting magnetic wedges. IEEE Trans. Ind. Electron. 2012, 59, 3768-3779. [CrossRef]

20. Aliabad, A.D.M.; Mirsalim, N.; Ershad, F. Line-start permanent-magnet motors: Significant improvements in starting torque, synchronization, and steady-state performance. IEEE Trans. Magn. 2010, 46, 4066-4072. [CrossRef] 
21. Aubry, J.; Ahmed, H.B.; Multon, B. Sizing Optimization methodology of a surface permanent magnet machine-converter system over a torque-speed operating profile: Application to a wave energy converter. IEEE Trans. Ind. Electron. 2012, 59, 2116-2125. [CrossRef]

22. Kano, Y.; Kosaka, T.; Matsui, N. A simple nonlinear magnetic analysis for axial-flux permanent-magnet machines. IEEE Trans. Ind. Electron. 2010, 57, 2124-2133. [CrossRef]

23. Hsieh, M.F.; Hsu, Y.C.; Dorrell, D.G. Design of large-power surface-mounted permanent-magnet motors using postassembly magnetization. IEEE Trans. Ind. Electron. 2010, 57, 3376-3384. [CrossRef]

(c) 2017 by the authors. Licensee MDPI, Basel, Switzerland. This article is an open access article distributed under the terms and conditions of the Creative Commons Attribution (CC BY) license (http:/ / creativecommons.org/licenses/by/4.0/). 